\title{
A NOVA LEI DE MIGRAÇÃO NO BRASIL: AVANÇOS E MELHORIAS NO CAMPO DOS DIREITOS HUMANOS
}

\author{
THE NEW MIGRATION LAW IN BRAZIL: PROGRESS AND IMPROVEMENTS IN THE \\ FIELD OF HUMAN RIGHTS
}

\author{
Sidney Guerra ${ }^{1}$
}

\begin{abstract}
Resumo
Atualmente os padrões de migrações podem ser vistos como um reflexo dos laços econômicos, políticos e culturais que estão em rápida mudança entre os países. Esse grande movimento migratório ocorre de maneira intensa em algumas regiões, seja em razão de guerras civis, por problemas étnicos, religiosos, ambientais e outras situações que se manifestam com frequência. Sendo um fenômeno de grande repercussão para o Estado, a matéria ganha relevo, com vários aspectos que precisam ser regulados pelo direito. Sendo assim, o presente trabalho apresenta a recente transição no ordenamento jurídico brasileiro da situação jurídica do estrangeiro em território nacional por meio da Lei 13.445, de 24 de maio de 2017. Desse modo, realizou-se breve apanhado histórico da antiga legislação, Lei n. 6.815, de 19 de agosto de 1980, inserida num contexto social e político diferente do atual cenário brasileiro neste campo. Após longos debates e estudos sobre a necessidade de conceber na ordem jurídica brasileira uma lei que retratasse a situação atual dos não nacionais, que até então eram vistos como hóspedes (estrangeiro), a matéria passou a ser regrada pela nova lei de migração. Assim sendo, os resultados dessa pesquisa retratam o avanço da postura brasileira na defesa dos direitos humanos e da dignidade da pessoa humana.
\end{abstract}

Palavras chave: Lei de Migração; Estrangeiro; Migrante; Direitos Humanos; Brasil.

\begin{abstract}
Nowadays patterns of migration can be seen as a reflection of the economic, political and cultural ties that are in rapid change between countries. This great migratory movement occurs in an intense way in some regions, due to civil wars, ethnic, religious, environmental problems and other situations that are frequently manifested. Being a phenomenon of great repercussion for the State, the matter gains importance, with several aspects that need to be regulated by law. Thus, the present work presents the recent transition in the Brazilian legal system of the legal situation of the foreigner in national territory through Law 13.445, of May 24, 2017. Thus, he made a brief history of the old legislation, Law no. 6,815, dated August 19, 1980, inserted in a social and political context different from the current brazilian scenario. After long debates and studies on the need to conceive in the Brazilian legal system a law that portrayed the current situation of non-nationals, who were previously considered as guests (foreigners), the matter was now governed by the new migration law. Thus, the results of this research portray the advance of the Brazilian position in the defense of human rights and the dignity of the human person.
\end{abstract}

Keywords: Migration Law; Foreigner; Migrant; Human Rights; Brazil.

\footnotetext{
1 Pós-Doutor pelo Centro de Estudos Sociais da Universidade de Coimbra. Pós-Doutor pelo Programa Avançado em Cultura Contemporânea da Universidade Federal do Rio de Janeiro (UFRJ). Professor Associado da Universidade Federal do Rio de Janeiro. Presidente do Instituto Brasileiro Pacificador (IBP). E-mail: sidneyguerra@terra.com.br
} 


\section{INTRODUÇÃO}

Atualmente os padrões de migrações podem ser vistos como um reflexo dos laços econômicos, políticos e culturais que estão em rápida mudança entre os países. Esse grande movimento migratório ocorre de maneira intensa em algumas regiões, seja em razão de guerras civis, por problemas étnicos ou religiosos, por falta de uma perspectiva melhor de vida e outras situações que se manifestam com frequência.

A mobilidade humana assume contornos complexos na atualidade e alcança o impressionante número de mais de 244 milhões de pessoas que se encontram fora do seu país de origem, ou seja, mais de 3,4\% da população mundial, segundo dados da Organização das Nações Unidas (ONU) referentes ao ano de 2015.

Sendo um fenômeno de grande repercussão para o Estado, com desdobramentos nos campos social, político, econômico, cultural e outros, a matéria ganha relevo, com vários aspectos que precisam ser regulados pelo direito.

No Brasil, até a edição da Lei 13.445, de 24 de maio de 2017, a matéria relativa a situação jurídica do estrangeiro estava prevista na Lei n. 6.815, de 19 de agosto de 1980, não havendo, até aquele momento, uma lei que tratasse de maneira específica sobre as migrações. A citada lei foi concebida no período que o Estado brasileiro era conduzido por militares e levava em conta aspectos voltados principalmente para a segurança nacional, apresentando-se como discriminatória e contrária aos fundamentos e princípios que norteiam a Carta Magna de 1988.

Após longos debates e estudos sobre a necessidade de conceber na ordem jurídica brasileira uma norma que retratasse a situação atual dos não nacionais, que até então eram vistos como hóspedes (estrangeiro), a matéria passou a ser regrada pela lei 13.445, de 24 de maio de 2017, que chegou em boa hora, tendo sido concebida em conformidade com a proteção conferida aos direitos humanos na Carta Magna brasileira.

O assunto além de atual é importante em razão das dúvidas que cercam o presente tema, bem como posicionamentos contrários e favoráveis. Assim, para efeito de elucidação de pontos que estão concebidos na nova lei, são colocados alguns questionamentos que serão respondidos ao longo do estudo: a) há diferença para o termo estrangeiro e migrante? b) Quais foram os principais aspectos que mudaram na nova lei? c) A lei 13445/2017 foi benéfica para o Estado brasileiro?

No presente estudo partir-se-á da lei 6815/80, para logo após verificar aspectos da lei 
13445/2017, que revoga a anterior. A proposta deste artigo é apresentar a transição de um modelo alicerçado na lógica da segurança nacional (estatuto do estrangeiro) para o que consagra a proteção dos direitos humanos (lei de migração), identificando os principais aspectos da nova lei em favor da pessoa humana. A leitura de doutrinas e o exame da legislação anterior (6815/80) e a vigente (13445/17) compõem o tratamento qualitativo do trabalho, notadamente bibliográfico e documental. Vale ressaltar que, apesar de ser um trabalho no campo jurídico, a pesquisa foi construída sobre alicerce multidisciplinar, destacando-se as referências das ciências sociais.

\section{AFINAL DE CONTAS: QUEM SÃO OS NACIONAIS, OS ESTRANGEIROS E OS MIGRANTES?}

Até a vigência da Lei 6815/80, chegava-se ao entendimento sobre quem era estrangeiro, partindo-se da identificação de quem era nacional, ou seja, o indivíduo que não encontrava-se no rol descrito do artigo 12 da Constituição de 1988, seja como brasileiro nato ou naturalizado, era considerado estrangeiro e, em situações excepcionais e diversas, apátrida.

A matéria sobre nacionalidade vem expressa na Carta Magna de 1988 e a situação jurídica do estrangeiro encontrava-se prevista, como mencionado, na Lei 6815/80, o conhecido Estatuto do Estrangeiro. ${ }^{2}$

O estudo relativo a nacionalidade 3 é comum para o Direito Constitucional com reflexos para o Direito Internacional posto que a Lei Maior apresenta os casos dos indivíduos que possuem a nacionalidade brasileira e por exclusão os que não se encontram nesse rol se apresentavam como estrangeiros. O artigo 12 da Constituição brasileira de 1988, prescreve que, in verbis:

Art. 12. São brasileiros:

I. natos:

a) os nascidos na República Federativa do Brasil, ainda que de pais estrangeiros, desde que estes não estejam a serviço de seu país;

b) os nascidos no estrangeiro, de pai brasileiro ou mãe brasileira, desde que qualquer deles esteja a serviço da República Federativa do Brasil;

\footnotetext{
${ }^{2}$ A Lei sobre Migração no Brasil - 13.445/2017 revogou a Lei 6815/80.

${ }_{3}^{3}$ Para REZEK, José Francisco Direito internacional público: curso elementar. 6. ed. São Paulo: Saraiva, 1996, p. 178, "nacionalidade é um vínculo político entre o Estado soberano e o indivíduo, que faz deste um membro da comunidade constitutiva da dimensão pessoal do Estado. Importante no âmbito do direito das gentes, esse vínculo político recebe, entretanto, uma disciplina jurídica de direito interno: a cada Estado incumbe legislar sobre sua própria nacionalidade, desde que respeitadas, no direito internacional, as regras gerais, assim como regras particulares com que acaso se tenha comprometido".
} 
c) os nascidos no estrangeiro de pai brasileiro ou de mãe brasileira, desde que sejam registrados em repartição brasileira competente ou venham a residir na República Federativa do Brasil e optem, em qualquer tempo, depois de atingida a maioridade, pela nacionalidade brasileira;

II. naturalizados:

a) os que, na forma da lei, adquiram a nacionalidade brasileira, exigidas aos originários de países de língua portuguesa apenas residência por um ano ininterrupto e idoneidade moral;

b) os estrangeiros de qualquer nacionalidade, residentes na República Federativa do Brasil há mais de quinze anos ininterruptos e sem condenação penal, desde que requeiram a nacionalidade brasileira.

No campo do direito das gentes, Sidney Guerra ${ }^{4}$ aponta alguns princípios relacionados à

matéria:

a) o direito das gentes confia à apreciação de cada Estado determinar como se adquire e se perde a sua nacionalidade;

b) nenhum Estado pode determinar as condições de aquisição e perda de uma nacionalidade estrangeira;

c) a apreciação estatal, na determinação da matéria, acha-se limitada pelo Direito Internacional;

d) as limitações resultam dos tratados, do costume e dos princípios gerais de Direito, universalmente reconhecidos;

e) uma declaração de nacionalidade feita por um Estado, no exercício de sua competência, tem efeitos jurídicos com relação aos demais Estados; f) não o terá, porém, se a declaração transgredir os limites impostos pelo direito das gentes;

f) os Estados só podem conferir sua nacionalidade a pessoas que com eles tenham relação real e estreita, tais como a filiação e o nascimento, no seu território;

g) a naturalização de um estrangeiro juridicamente capaz não poderá efetivar-se sem o seu consentimento;

h) uma naturalização que não exija o consentimento dos interessados só é possível em caso de cessão territorial, quando os indivíduos tenham seu domicílio ordinário no território cedido, ressalvadas as disposições convencionais em sentido oposto;

i) o princípio de que a nacionalidade implica uma relação efetiva e permanente como Estado de que é súdito acarreta, entre outras consequências, a de que as disposições que fazem depender a perda da nacionalidade de uma exclusão formal da agrupação estatal são ineficazes perante o direito das gentes, se a pessoa em questão, estabelecida permanentemente em um país estrangeiro, tiver adquirido a nacionalidade deste sem ter sido excluída da agrupação estatal anterior;

j) somente em seu território tem o Estado o direito de baixar normas sobre a matéria, não tendo qualquer valor, perante o direito

\footnotetext{
${ }^{4}$ Verdross apud GUERRA, Sidney. Curso de direito internacional público. 10. ed. São Paulo: Saraiva, 2016, p. 370.
} 
internacional, as naturalizações levadas a efeito em território ocupado por determinada potência.

O sujeito natural do Estado é o nacional, que em seu conjunto corresponde a ideia de povo, que não pode ser confundido com população por se tratar de conceito que designa o número de habitantes de um território num determinado momento. Já os estrangeiros, por exclusão, eram identificados como todos aqueles que não se enquadravam na categoria de nacionais.

Todavia, a matéria sofreu profunda mudança a partir do momento que a Lei 13.445/ 2017 entrou em vigência. A nova lei trata dos direitos e os deveres do migrante e do visitante no Brasil; regula a entrada e a permanência de estrangeiros; e estabelece normas de proteção ao brasileiro no exterior. Também estabelece alterações na nomenclatura do não nacional, substituindo a figura do estrangeiro para a do migrante, como se depreende da leitura do artigo 1ㅇ:

Artigo 10 Esta Lei dispõe sobre os direitos e os deveres do migrante e do visitante, regula a sua entrada e estada no País e estabelece princípios e diretrizes para as políticas públicas para o emigrante.

$\S 1$ 을 Para os fins desta Lei, considera-se:

I. (VETADO);

II. imigrante: pessoa nacional de outro país ou apátrida que trabalha ou reside e se estabelece temporária ou definitivamente no Brasil;

III. emigrante: brasileiro que se estabelece temporária ou definitivamente no exterior;

IV. residente fronteiriço: pessoa nacional de país limítrofe ou apátrida que conserva a sua residência habitual em município fronteiriço de país vizinho;

V. visitante: pessoa nacional de outro país ou apátrida que vem ao Brasil para estadas de curta duração, sem pretensão de se estabelecer temporária ou definitivamente no território nacional;

VI. apátrida: pessoa que não seja considerada como nacional por nenhum Estado, segundo a sua legislação, nos termos da Convenção sobre o Estatuto dos Apátridas, de 1954, promulgada pelo Decreto № 4.246, de 22 de maio de 2002, ou assim reconhecida pelo Estado brasileiro.

Em um primeiro momento, as mudanças produzidas na lei 13445/2017, que identifica a

figura do imigrante e do visitante, ao invés do termo estrangeiro, pode aparentar que trata-se apenas de aspecto terminológico. Todavia, a lei 6815/80 estabelecia várias restrições ${ }^{5}$ aos

\footnotetext{
${ }^{5}$ Alguns aspectos que estavam concebidos na lei 6815/80: proíbe ao estrangeiro exercer atividade de natureza política; organizar, criar ou manter sociedade ou quaisquer entidades de caráter político, ainda que tenham por fim apenas a propaganda ou a difusão, exclusivamente entre compatriotas, de ideias, programas ou normas de ação de partidos políticos do país de origem; organizar desfiles, passeatas, comícios e reuniões de qualquer natureza, ou deles participar (artigo 107); proíbe ao estrangeiro ser representante de sindicato ou associação profissional, ou de entidade fiscalizadora do exercício de profissão regulamentada (artigo 106); proíbe ao estrangeiro possuir, manter ou operar, mesmo como
} 
estrangeiros que foram suprimidas na nova lei que, como mencionado acima, foi concebida em conformidade com as normas (regras e princípios) consagrados pela República Federativa do Brasil.

\section{A NOVA LEI DE MIGRAÇÃO}

O Senado Federal aprovou no dia 18 de abril de $2017^{6}$, por unanimidade, o projeto Substitutivo da Câmara dos Deputados n. 7/2016 que revoga o Estatuto do Estrangeiro, criado durante o governo militar, e instituiu a nova Lei de Migração brasileira (Lei 13.345/2017).

Indubitavelmente que a nova lei coloca o Brasil em posição de vanguarda nesta matéria, posto que defere aos imigrantes uma série de prerrogativas que até então eram conferidos apenas para os seus nacionais. Entre as principais mudanças introduzidas pela nova Lei de Migração, estão a desburocratização do processo de regularização migratória, a institucionalização da política de vistos humanitários, a não criminalização por razões migratórias, além de conferir uma série de direitos aos migrantes que até então não eram garantidos.

Como mencionado anteriormente, a matéria estava regrada na ordem interna pela Lei n. 6.815, de 19 de agosto de 1980, que tratava da situação jurídica do estrangeiro no Brasil e que já não atendia aos anseios do grande número de pessoas que se instalaram no Brasil, pelos mais diversos motivos, ao longo dos anos.

Não se pode olvidar que à época que o estatuto foi concebido, a prioridade consagrada na legislação encontrava-se alicerçada em questões relativas à segurança nacional, aos interesses socioeconômicos do Brasil e ao trabalhador nacional. O termo estrangeiro adotado pela norma citada, indicava a existência de um indivíduo que "é natural de outro país; que não

amador, aparelho de radiodifusão, de radiotelegrafia e similar; ou ainda prestar assistência religiosa a estabelecimentos de internação coletiva (artigo 106); permite ao Ministro da Justiça, sempre que considerar conveniente aos interesses nacionais, impedir a realização, por estrangeiros, de conferências, congressos e exibições artísticas ou folclóricas (artigo 110);permite expulsar o estrangeiro que, de qualquer forma, atentar contra a segurança nacional, a ordem política ou social, a tranquilidade ou moralidade pública e a economia popular, ou cujo procedimento o torne nocivo à conveniência e aos interesses nacionais; entregar-se à vadiagem ou à mendicância; ou desrespeitar proibição especialmente prevista em lei para estrangeiro (artigo 65).

${ }^{6}$ A nova Lei de Migração foi proposta pelo atual ministro das relações exteriores, senador Aloysio Nunes, em 2013. Aprovado pelo plenário do Senado em agosto de 2015, o PLS 288/2013 seguiu para a Câmara, foi rebatizado de PL 2516/2015 e tramitou na sob relatoria do deputado Orlando Silva (PCdoB-SP), em uma Comissão Especial. Aprovado pelo plenário da Câmara em dezembro de 2016, o projeto voltou para o Senado. O novo relator designado foi o senador Tasso Jereissati (PSDB-CE), que recomendou a aprovação de um texto muito próximo ao que voltara da Câmara. A lei foi aprovada por 43 dos senadores presentes e teve quatro votos contrários e uma abstenção. 
faz parte de uma família, de um grupo".

No caso da nova legislação, o legislador preferiu adotar a figura do migrante e do visitante (art. 1), em conformidade com a política consagrada na atualidade em prol dos direitos humanos. De certo modo, o termo empregado na lei 13445/2017 faz com que o indivíduo, que não seja nacional do Estado, não se sinta estranho e preterido no local que se encontra, como se um forasteiro fosse. Aliás, o termo estrangeiro remete a esta ideia, conforme o entendimento esposado anteriormente.

Diferentemente do estatuto do estrangeiro, a nova Lei de Migração trata o imigrante como um sujeito de direitos e garante em todo o território nacional, em condição de igualdade com os nacionais, uma série de direitos que anteriormente não eram concebidos, a saber: a inviolabilidade do direito à vida, à liberdade, à igualdade, à segurança e à propriedade; direitos e liberdades civis, sociais, culturais e econômicos; direito à liberdade de circulação em território nacional; direito à reunião familiar do imigrante com seu cônjuge ou companheiro e seus filhos, familiares e dependentes; medidas de proteção a vítimas e testemunhas de crimes e de violações de direitos; direito de transferir recursos decorrentes de sua renda e economias pessoais a outro país, observada a legislação aplicável; direito de reunião para fins pacíficos; direito de associação, inclusive sindical, para fins lícitos; acesso a serviços públicos de saúde e de assistência social e à previdência social, nos termos da lei, sem discriminação em razão da nacionalidade e da condição migratória; amplo acesso à justiça e à assistência jurídica integral gratuita aos que comprovarem insuficiência de recursos; direito à educação pública, vedada a discriminação em razão da nacionalidade e da condição migratória; garantia de cumprimento de obrigações legais e contratuais trabalhistas e de aplicação das normas de proteção ao trabalhador, sem discriminação em razão da nacionalidade e da condição migratória; isenção das taxas de que trata esta Lei, mediante declaração de hipossuficiência econômica, na forma de regulamento; direito de acesso à informação e garantia de confidencialidade quanto aos dados pessoais do imigrante, nos termos da Lei no 12.527, de 18 de novembro de 2011; direito a abertura de conta bancária; direito de sair, de permanecer e de reingressar em território nacional, mesmo enquanto pendente pedido de residência, de prorrogação de estada ou de transformação de visto em residência; e direito do imigrante de ser informado sobre as garantias que the são asseguradas para fins de regularização migratória.

Ademais, é permitido ao imigrante exercer cargo, emprego e função pública, conforme definido em edital, excetuados aqueles reservados para brasileiro nato, nos termos da 
Constituição Federal ${ }^{7}$, não sendo exigível ao migrante prova documental impossível ou descabida que dificulte ou impeça o exercício de seus direitos, inclusive o acesso a cargo, emprego ou função pública.

Estas mudanças ${ }^{8}$ que foram propostas pela nova lei tem gerado muitas críticas por determinados setores, considerados mais conservadores, sobre as grandes possibilidades e oportunidades que passarão a ser conferidas aos indivíduos que não possuem a nacionalidade brasileira.

Com efeito, a novel legislação procura dar concretude ao que estabelece o texto constitucional brasileiro, in casu o artigo 5 que consagra o princípio da igualdade entre os brasileiros e os não brasileiros, pugnando de maneira clara o combate à discriminação, à xenofobia e outras práticas que sejam consideradas atentatórias aos direitos humanos.

Em interessante abordagem Asano e Timo $^{9}$ afirmam que nos últimos quatro anos, vários debates em torno das migrações foram impulsionados no Brasil, principalmente pela chegada de migrantes haitianos, que evidenciou uma série de questões como: ausência de políticas públicas para o acolhimento, obstáculos burocráticos para se obter documentação, discriminação e dificuldades de integração, que culminaram em vários eventos e debates públicos que culminaram ao final com a nova Lei de Migração que estivesse em conformidade com a política brasileira em prol dos direitos humanos. E no contraponto das questões contrárias à nova legislação as autoras ${ }^{10}$ advertem que a adoção de medidas restritivas para o acesso dos migrantes em território nacional não são consideradas adequadas, pois aumentam a insegurança e adoção de mecanismos criminosos e, por isso mesmo, a nova legislação

7 Artigo 12. § 3o São privativos de brasileiro nato os cargos: I - de Presidente e Vice-Presidente da República; II - de Presidente da Câmara dos Deputados; III - de Presidente do Senado Federal; IV - de Ministro do Supremo Tribunal Federal; V - da carreira diplomática; VI - de oficial das Forças Armadas; VII de Ministro de Estado da Defesa.

8 Diferenças básicas entre a Lei 6815/80 e a Lei 13.445/2017: a Lei 6815/80 considera o estrangeiro um tema de segurança nacional; é incompatível com a Constituição Federal e os tratados internacionais de direitos humanos; dá ao Estado a possibilidade de decidir ao seu bel-prazer quem pode entrar e permanecer no Brasil; vincula a regularização migratória ao emprego formal; fragmenta atendimento a migrante em órgãos estatais diversos. A Lei 13.445/2017 considera os migrantes um tema de direitos humanos; encoraja a regularização migratória; o migrante regular fica menos vulnerável e tem oportunidade de ser incluído socialmente; possibilita a entrada regular de quem busca um emprego no Brasil; estabelece órgão estatal especializado para atendimento dos migrantes.

${ }^{9}$ ASANO, Camila Lissa; TIMO, Pétalla Brandão. A nova Lei de Migração no Brasil e os direitos humanos. Disponível em https://br.boell.org/pt-br/2017/04/17/nova-lei-de-migracao-no-brasil-e-os-direitoshumanos. Acesso em 03/05/2017.

10 Idem: "Conforme demonstram diversos exemplos ao redor do mundo, são ineficazes todas as tentativas contenção dos fluxos migratórios pela via repressiva de endurecimento do controle fronteiriço. Apertar o controle serve apenas para incentivar meios alternativos como os coiotes, que aumentam ainda mais os abusos contra os migrantes e instigam insegurança para a população em geral." 
migratória precisava observar ao menos cinco propostas:

1. A garantia dos direitos humanos das pessoas migrantes, sem discriminação de nenhum tipo e independente da situação migratória;

2. O estabelecimento de procedimentos de regularização migratória rápidos, efetivos e acessíveis como uma obrigação do Estado e um direito do migrante;

3. A não criminalização das migrações, incluindo o princípio de não detenção do migrante por razões vinculadas à sua situação migratória;

4. O controle judicial e o acesso dos migrantes a recursos efetivos sobre todas as decisões do poder público que possam gerar vulneração de seus direitos;

5. A criação de uma instituição nacional autônoma, com um corpo profissional permanente e especializado e mecanismos de supervisão e controle social, responsável pela aplicação da lei.

Quanto aos direitos sociais, tratou da inclusão social, laboral e produtiva do migrante por meio de políticas públicas; acesso igualitário e livre do imigrante a serviços, programas e benefícios sociais, bens públicos, educação, assistência jurídica integral pública, trabalho, moradia, serviço bancário e seguridade social. Neste campo, a nova legislação também adotou entendimento esposado pela Corte Interamericana de Direitos Humanos desde a consulta formulada pelos Estados Unidos Mexicano ${ }^{11}$, em 10 de maio de 2002, que resultou na Opinião

\footnotetext{
${ }^{11}$ En el marco del principio de igualdad jurídica consagrado en el artículo II de la Declaración Americana, en el artículo 24 de la Convención Americana, en el artículo 7 de la Declaración Universal y en el artículo 26 del Pacto [Internacional de Derechos Civiles y Políticos ...], 1) ¿ंPuede un Estado americano, en relación con su legislación laboral, establecer un trato perjudicialmente distinto para los trabajadores migratorios indocumentados en cuanto al goce de sus derechos laborales respecto de los residentes legales o los ciudadanos, en el sentido de que dicha condición migratoria de los trabajadores impide per se el goce de tales derechos? 2.1) Los artículos 2, párrafo 1 de la Declaración Universal y II de la Declaración Americana y los artículos 2 y 26 del Pacto [Internacional de Derechos Civiles y Políticos], así como 1 y 24 de la Convención Americana, ¿̇deben interpretarse en el sentido de que la legal estancia de las personas en el territorio de un Estado americano es condición necesaria para que dicho Estado respete y garantice los derechos y libertades reconocidos en dichas disposiciones a las personas sujetas a su jurisdicción? 2.2) A la luz de las disposiciones citadas en la pregunta anterior[,] ¿puede considerarse que la privación de uno o más derechos laborales, tomando como fundamento de tal privación la condición indocumentada de un trabajador migratorio, es compatible con los deberes de un Estado americano de garantizar la no discriminación y la protección igualitaria y efectiva de la ley que le imponen las disposiciones mencionadas? 3) ¿Cuál sería la validez de la interpretación por parte de un Estado americano en el sentido de subordinar o condicionar de cualquier forma la observancia de los derechos humanos fundamentales, incluyendo el derecho a la igualdad ante la ley y a la igual y efectiva protección de la misma sin discriminación, a la consecución de objetivos de política migratoria contenidos en sus leyes, independientemente de la jerarquía que el derecho interno atribuya a tales leyes, frente a las obligaciones internacionales derivadas del Pacto Internacional de Derechos Civiles y Políticos y de otras obligaciones del derecho internacional de los derechos humanos oponibles erga omnes? Habida cuenta del desarrollo progresivo del derecho internacional de los derechos humanos y su codificación, en especial a través de las disposiciones invocadas de los instrumentos mencionados en la presente solicitud, 4) ¿Qué carácter tienen hoy el principio de no discriminación y el derecho a la protección igualitaria y efectiva de la ley en la jerarquía normativa que establece el derecho internacional general, y en ese contexto, pueden considerarse como la expresión de normas de ius cogens? Si la respuesta a esta
} 
Consultiva n. 18 (OC18-03) de 17 de setembro de 2003, cujos resultados podem ser apresentados de maneira resumida da seguinte forma:

La Corte establece que el principio de no discriminación se encuentra recogido en diversos instrumentos internacionales y ha sido repetido por diversos órganos internacionales como una piedra angular de la protección de los derechos humanos. Al no poder ser evitado de ninguna manera, se concluye que tiene carácter de ius cogens. Dado el carácter de ius cogens del principio de no discriminación, ni el estatus de migrante ni tampoco el estatus de migrante indocumentado puede ser justificante para la realización de actos discriminatorios. El Estado tiene el deber de respetar el debido proceso en los procesos penales o administrativos a los que se someta a los migrantes indocumentados y no puede utilizar su estatus para evitar el cumplimiento de este derecho. En las relaciones privadas laborales, el Estado tiene un deber de garantía por el cual debe procurar que, sin importar el estatus migratorio, todo trabajador pueda disfrutar de los derechos laborales que le corresponden. Así, debe evitar que se realicen actos discriminatorios en el contexto de las relaciones laborales.

A nova lei passou a ser alvo de elogios ${ }^{12}$ e também de ataques ${ }^{13}$ por parte de vários segmentos da sociedade brasileira. Apesar de toda carga de "paixão" existente para aqueles

segunda pregunta resultase afirmativa, ¿qué efectos jurídicos se derivan para los Estados miembros de la OEA, individual y colectivamente, en el marco de la obligación general de respetar y garantizar, conforme al artículo 2 párrafo 1 del Pacto [Internacional de Derechos Civiles y Políticos], el cumplimiento de los derechos humanos a que se refieren el artículo 3, inciso (I) y el artículo 17 de la Carta de la OEA? Disponível em http://www.corteidh.or.cr/cf/Jurisprudencia2/index.cfm?lang=es. Acesso em 15/05/17.

12 O senador Tasso Jereissati (PSDB-CE) afirmou, em entrevista à Rádio Senado, que o projeto da nova Lei de Migração tem uma "visão nova" sobre os estrangeiros no Brasil. A ideia, disse ele, é garantir direitos para que o imigrante possa trabalhar e contribuir para o crescimento do país. Segundo o senador, o texto aprovado recentemente pelo Senado depois das alterações feitas pela Câmara dos Deputados (SCD 7/2016) muda a "visão econômica" do Estatuto do Estrangeiro (Lei 6.815/80). Disponível em http://www12.senado.leg.br/noticias/audios/2017/04/tasso-nova-lei-de-migracao-da-ao-estrangeirooportunidade-de-contribuir-para-o-brasil Acesso em 06 de maio de 2017.

13 No dia 26 de março a direita saiu às ruas em todo o Brasil. Apesar de os protestos terem sido convocados com o intuito de defender a reforma da previdência, apareceu uma miríade de pautas, que iam desde questões econômicas até questões de cunho moral. (...) Apesar de o Brasil não estar recebendo um número elevado de imigrantes e refugiados, a narrativa do "estrangeiro" como um perigo começa a ressurgir por aqui, justo quando o país está prestes a modificar sua legislação migratória. (...) Ávidos por encontrar um culpado para as nossas crises, esses grupos conservadores buscam despertar nas pessoas o sentimento de medo. No ato do dia 26 de março, uma liderança desses grupos, falando no carro de som em plena Avenida Paulista, afirmou que a nova Lei de Migração "escancara nossas fronteiras e coloca para dentro quem quiser entrar". Acrescentou ainda que isso irá sobrecarregar os serviços públicos - como se fossem os migrantes os responsáveis pela má qualidade dos serviços públicos no Brasil, historicamente negligenciados pelo poder público. Essa liderança disse também que, no período de um ano, irá entrar no país uma quantidade de "estrangeiros" equivalente à atual população brasileira e que isso poderá até modificar a língua materna - sem apresentar dados que de fato embasem essas afirmações. O elemento novo dessa narrativa - muito comum em discursos xenófobos - é que agora estão dizendo que "os fluxos migratórios ocorrem porque o Partido dos Trabalhadores (PT) teria perdido maioria e que estaria tentando importar pessoas para compor uma nova maioria". Disponível em 
que defendem e para os que atacam a nova lei, o fato é que a matéria corresponde a um grande avanço neste campo.

Em verdade, o que ela pretende é dar concretude ao texto constitucional brasileiro, in casu o artigo 5, que consagra o princípio da igualdade entre os brasileiros e os não brasileiros, pugnando de maneira clara o combate à discriminação, à xenofobia e outras práticas que sejam consideradas atentatórias aos direitos humanos.

A nova lei sobre a política migratória brasileira caminhou bem ao consagrar os princípios da universalidade, indivisibilidade e interdependência dos direitos humanos; repúdio e prevenção à xenofobia, ao racismo e a quaisquer formas de discriminação; não criminalização da imigração; não discriminação em razão dos critérios ou dos procedimentos pelos quais a pessoa foi admitida em território nacional. Avançou também nos aspectos relativos à promoção de entrada regular e de regularização documental; acolhida humanitária; igualdade de tratamento e de oportunidade ao migrante e a seus familiares etc.

\section{A ADMISSÃO E A RETIRADA COMPULSÓRIA DO MIGRANTE}

$\mathrm{O}$ ato de ingresso e permanência do estrangeiro em território nacional relaciona-se à discricionariedade do Estado, podendo este aceitar ou não que uma determinada pessoa permaneça em seu território, como por exemplo, no caso em que um indivíduo tenha atentado contra a segurança do Estado (como na prática de atos terroristas). Há de ressaltar que o Estado não pode se prender a questões relativas a raça, sexo, idioma ou religião.

É de competência exclusiva de cada Estado legislar sobre a admissão e expulsão de estrangeiros em sua base física. Deste modo, várias são as restrições que os Estados adotam no tocante à admissão de estrangeiros em seus territórios. Uns cobram taxas de admissão, outros fixam quota de imigração e quase todos exigem a apresentação de passaportes.

A Lei 13.445/2017 também dispôs sobre esta matéria. Entretanto, diferentemente da lei do estrangeiro, procura apresentar critérios objetivos que garantem, de forma mais satisfatória, proteção jurídica ao não nacional.

Para ser admitido em território brasileiro o migrante ${ }^{14}$ deverá ter em sua posse um

http://migramundo.com/nova-lei-de-migracao-e-migrantes-sob-ataque-um-relato-dos-protestos-de-26de-marco-no-brasil/ Acesso em 06 de maio de 2017.

14 Os artigos 10 e 11 versam sobre a não concessão do visto: “Art. 10. Não se concederá visto: I - a quem não preencher os requisitos para o tipo de visto pleiteado; II - a quem comprovadamente ocultar condição impeditiva de concessão de visto ou de ingresso no País; ou III - a menor de 18 (dezoito) anos desacompanhado ou sem autorização de viagem por escrito dos responsáveis legais ou de autoridade 
documento que o identifique sendo que a nova legislação admite como documentos de viagem o passaporte; o laissez-passer; a autorização de retorno; o salvo-conduto; a carteira de identidade de marítimo; a carteira de matrícula consular; o documento de identidade civil ou documento estrangeiro equivalente, quando admitidos em convenção ou tratado internacional; o certificado de membro de tripulação de transporte aéreo; e outros que vierem a ser reconhecidos pelo Estado brasileiro em regulamento.

A nova lei apresenta o visto como o documento que dá a seu portador expectativa de ingresso em território nacional (artigo 6), podendo ser expedido por embaixadas, consuladosgerais, consulados, vice-consulados e, quando habilitados pelo órgão competente do Poder Executivo, por escritórios comerciais e de representação do Brasil no exterior (artigo 7). Assim, serão concedidos pelo Estado brasileiro ao solicitante que pretenda ingressar ou permanecer no território nacional, os seguintes tipos de vistos: visita; temporário; diplomático; oficial; e de cortesia (artigo 12), sendo que poderão ser cobrados taxas e emolumentos consulares pelo processamento do visto.

No caso do apátrida, tema que tem sido objeto de reflexões no âmbito do direito internacional ${ }^{15}$, a seção II da Lei n. 13.445/2017 conferiu proteção para o apátrida. Todavia, a matéria ainda deverá ser regulamentada, conforme estabelece o artigo 26, para que possa garantir proteção especial, bem como seja consolidado processo simplificado de naturalização. Neste caso, o processo de que trata o referido artigo será iniciado tão logo seja reconhecida a situação de apatridia, sendo certo que durante a tramitação do processo de reconhecimento da condição de apátrida, incidem todas as garantias e mecanismos protetivos e de facilitação da inclusão social relativos à Convenção sobre o Estatuto dos Apátridas de 1954, promulgada pelo Decreto o 4.246, de 22 de maio de 2002, à Convenção relativa ao Estatuto dos Refugiados, promulgada pelo Decreto $n^{\circ} 50.215$, de 28 de janeiro de 1961, e à Lei $n^{\circ} 9.474$, de 22 de julho de 1997.

competente. Art. 11. Poderá ser denegado visto a quem se enquadrar em pelo menos um dos casos de impedimento definidos nos incisos I, II, III, IV e IX do art. 45. Parágrafo único. A pessoa que tiver visto brasileiro denegado será impedida de ingressar no País enquanto permanecerem as condições que ensejaram a denegação."

${ }^{15}$ Embora o tema dos refugiados e apátridas, em algumas circunstâncias sejam tratados em conjunto, as situações que versam sobre estes indivíduos é diferenciada. A propósito, esclarecedor o magistério de DAILLIER, Patrick; PELLET, Alain. Droit international public. 7. ed. Paris: LGDJ, 2002, p. 677: "Bien que leur étude soit em general effectuée simultanément, la situation des réfugiés et celle des apatrides sont clairement distinctes au point de vue juridique. Les premiers sont des étrngers placés dans une situation spéciale vis a vis de l'Etat d'accueil qui leur acorde as protection du fait des persécutions dont ils sont victimes dans leur propre pays; les seconds sont des personnes qu'aucun État ne considere comme par aplication de as législation." 
Impende assinalar que são aplicados ao apátrida residente todos os direitos atribuídos ao migrante relacionados no art. 4 - da Lei $13.445 / 2017$, sendo assegurados os direitos e garantias previstos na Convenção sobre o Estatuto dos Apátridas, de 1954, promulgada pelo Decreto $n^{0} 4.246$, de 22 de maio de 2002, bem como outros direitos e garantias reconhecidos pelo Brasil.

Com efeito, o processo de reconhecimento da condição de apátrida tem como objetivo verificar se o solicitante é considerado nacional pela legislação de algum Estado e poderá considerar informações, documentos e declarações prestadas pelo próprio solicitante e por órgãos e organismos nacionais e internacionais. Sendo reconhecida a condição de apátrida, nos termos do inciso $\mathrm{VI}$ do $\S 1^{\circ}$ do art. 1ํㅡㄴ o solicitante será consultado sobre o desejo de adquirir a nacionalidade brasileira e caso o apátrida opte pela naturalização, a decisão sobre o reconhecimento será encaminhada ao órgão competente do Poder Executivo para publicação dos atos necessários à efetivação da naturalização no prazo de 30 (trinta) dias. Por fim, vale destacar que o apátrida reconhecido que não opte pela naturalização imediata terá a autorização de residência outorgada em caráter definitivo e apenas deixará de ter a proteção do Estado brasileiro, conferida pela Lei 13.445/2017, nos casos de renúncia; prova da falsidade dos fundamentos invocados para o reconhecimento da condição de apátrida; ou a existência de fatos que, se fossem conhecidos por ocasião do reconhecimento, teriam ensejado decisão negativa. Quanto ao asilo, que pode ser territorial ou diplomático, a lei também dispôs sobre a matéria como sendo um instrumento protetivo à pessoa humana, não sendo concedido para quem tenha cometido crime de genocídio, crime contra a humanidade, crime de guerra ou crime de agressão, nos termos do Estatuto de Roma do Tribunal Penal Internacional, de 1998. ${ }^{16}$

Uma vez admitido em território nacional, o indivíduo ${ }^{17}$ estará sujeito às leis locais,

\footnotetext{
${ }^{16}$ A matéria está no capítulo XIII do livro de GUERRA, Sidney. Curso de direito internacional público. 10. ed. São Paulo: Saraiva, 2016.

$17 \mathrm{O}$ artigo 30, incisos I e II, apresentam os casos que podem ser autorizadas a residência do imigrante, residente fronteiriço ou visitante, Art. 30. A residência poderá ser autorizada, mediante registro, ao imigrante, ao residente fronteiriço ou ao visitante que se enquadre em uma das seguintes hipóteses: I - a residência tenha como finalidade: a) pesquisa, ensino ou extensão acadêmica; b) tratamento de saúde; c) acolhida humanitária; d) estudo; e) trabalho; f) férias-trabalho; g) prática de atividade religiosa ou serviço voluntário; h) realização de investimento ou de atividade com relevância econômica, social, científica, tecnológica ou cultural; i) reunião familiar; II - a pessoa: a) seja beneficiária de tratado em matéria de residência e livre circulação; b) seja detentora de oferta de trabalho; c) já tenha possuído a nacionalidade brasileira e não deseje ou não reúna os requisitos para readquiri-la; d) (vetado); e) seja beneficiária de refúgio, de asilo ou de proteção ao apátrida; f) seja menor nacional de outro país ou apátrida, desacompanhado ou abandonado, que se encontre nas fronteiras brasileiras ou em território nacional; g) tenha sido vítima de tráfico de pessoas, de trabalho escravo ou de violação de direito agravada por sua condição migratória; h) esteja em liberdade provisória ou em cumprimento de pena no Brasil.
} 
observando-se situações excepcionais correspondentes às imunidades concebidas nos documentos internacionais. A lei também estabeleceu em que circunstâncias que o indivíduo não será aceito no território nacional, conforme preceitua o artigo 45:

Poderá ser impedida de ingressar no País, após entrevista individual e mediante ato fundamentado, a pessoa: I - anteriormente expulsa do País, enquanto os efeitos da expulsão vigorarem; II - condenada ou respondendo a processo por ato de terrorismo ou por crime de genocídio, crime contra a humanidade, crime de guerra ou crime de agressão, nos termos definidos pelo Estatuto de Roma do Tribunal Penal Internacional, de 1998, promulgado pelo Decreto $n^{\circ} 4.388$, de 25 de setembro de 2002; III - condenada ou respondendo a processo em outro país por crime doloso passível de extradição segundo a lei brasileira; IV que tenha o nome incluído em lista de restrições por ordem judicial ou por compromisso assumido pelo Brasil perante organismo internacional; $\checkmark$ - que apresente documento de viagem que: a) não seja válido para o Brasil; b) esteja com o prazo de validade vencido; ou c) esteja com rasura ou indício de falsificação; $\mathrm{VI}$ - que não apresente documento de viagem ou documento de identidade, quando admitido; VII - cuja razão da viagem não seja condizente com o visto ou com o motivo alegado para a isenção de visto; VIII - que tenha, comprovadamente, fraudado documentação ou prestado informação falsa por ocasião da solicitação de visto; ou IX - que tenha praticado ato contrário aos princípios e objetivos dispostos na Constituição Federal.

Com efeito, da mesma forma que o Estado pode acolher um indivíduo de nacionalidade distinta dos seus, também poderá retirá-lo. A matéria, na nova legislação, vem expressa no capítulo VI que versa sobre as medidas de retirada compulsória.

A primeira medida que poderá ser adotada pelo Estado é a repatriação que consiste na devolução de pessoa em situação de impedimento ao país de procedência ou de nacionalidade, sendo certo que tal medida não será aplicada para pessoa em situação de refúgio ou de apatridia, de fato ou de direito; aos menores de dezoito anos desacompanhados ou separados de suas famílias, exceto nos casos em que se demonstrar favorável; para a garantia de seus direitos ou para a reintegração a sua família de origem, ou a quem necessite de acolhimento humanitário; nem, em qualquer caso, de devolução para país ou região que possa apresentar risco à sua vida, integridade pessoal ou liberdade.

Ainda no capítulo VI, nas seções de número III e IV, a legislação contemplou aspectos relativos à deportação e expulsão, respectivamente. Antes, porém, de apresenta-los, importante frisar que a nova lei ao consagrar princípios e diretrizes que devem pautar o desenvolvimento da matéria no Brasil, garantiu a não criminalização por razões migratórias, isto é, independentemente do motivo que se deu a mesma, o indivíduo não estará sujeito a deportação, bem como não poderá ter a sua liberdade cerceada por não estar de posse de sua 
documentação, diferentemente do que acontecia sob a égide da lei do estrangeiro. Sobre este ponto, há estudos que indicam que a implementação desta matéria será um grande desafio, principalmente nos controles que são realizados em zonas de fronteira e a incidência de deportações arbitrárias, como se vê:

Para ilustrar, podemos citar casos recentes ocorridos no Estado de Roraima -localizado na fronteira do Brasil com Venezuela e Guiana-, onde venezuelanos foram deportados pela polícia ao longo do ano de 2016, mesmo aqueles que solicitaram o refúgio. Uma ação judicial impediu que 450 venezuelanos fossem coletivamente deportados no mês de dezembro de 2016. Há, ademais, casos de repatriação em que migrantes são colocados em um limbo jurídico e mantidos em áreas de fiscalização, a exemplo do chamado "espaço Conector" do Aeroporto Internacional de Guarulhos, São Paulo, arbitrariamente e por tempo indeterminado, sem a assistência necessária e a garantia do devido processo legal, até conseguirem verbalizar um pedido de refúgio ou serem devolvidos para o país de origem. De janeiro de 2015 até abril de 2016, 1814 migrantes foram mantidos no espaço Conector, dos quais 494 eram solicitantes de refúgio que procuravam proteção no país e foram impedidos de ingressar diretamente em solo brasileiro. Importante que neste ponto, pessoas em situação de refúgio não podem ser devolvidas para o país de origem por conta da sua vida estar em risco, de acordo com o princípio fundamental de non-refoulement (não devolução) do Direito Internacional Público e conforme consta na legislação brasileira que trata do refúgio (Lei 9474/1997). ${ }^{18}$

A propósito, quanto ao residente fronteiriço, para facilitar sua livre circulação, o Estado poderá conceder autorização para a realização de atos da vida civil, mediante requerimento do interessado. Esta medida foi bastante adequada, principalmente se for levado em conta as longas fronteiras do Estado brasileiro com os países da América do Sul (exceção do Equador e Chile apenas). Assim, o residente fronteiriço detentor da autorização gozará das garantias e dos direitos assegurados pelo regime geral de migração da nova Lei, podendo ser cancelado, a qualquer tempo, se o titular tiver fraudado documento ou utilizado documento falso para obtêlo; obtiver outra condição migratória; sofrer condenação penal; ou exercer direito fora dos limites previstos na autorização.

No caso da deportação, esta ocorre quando se promove a retirada do imigrante que, ingressando no país ou neste se encontrando irregularmente, não se retirar voluntariamente no prazo que the for determinado. Trata-se, portanto, de medida decorrente de procedimento administrativo que consiste na retirada compulsória de indivíduo que se encontre em situação migratória irregular em território nacional. Para tanto, a deportação será precedida de notificação pessoal ao imigrante, da qual constem, expressamente, as irregularidades

${ }^{18}$ ASANO, Camila Lissa; TIMO, Pétalla Brandão, op. cit. 
verificadas e prazo para a regularização não inferior a sessenta dias, podendo ser prorrogado, por igual período, por despacho fundamentado e mediante compromisso de o imigrante manter atualizadas suas informações domiciliares

Impende assinalar que no caso de incidência da deportação não haverá por parte do indivíduo o cometimento de crime e sim a não observância de determinados requisitos legais para sua permanência no Estado. A nova lei inovou ao dispor que mesmo sendo notificado o indivíduo não ficará impedido de circular livremente no território nacional, devendo, todavia, o imigrante informar seu domicílio e suas atividades. Apenas com o vencimento do prazo para que o mesmo regularize sua situação com o Estado brasileiro, observando-se o princípio constitucional do contraditório e ampla defesa, é que a deportação poderá ser executada, não excluindo eventuais direitos adquiridos ao deportado, em relações contratuais ou decorrentes da lei brasileira. ${ }^{19}$

No caso da expulsão, a nova legislação a trata como medida administrativa de retirada compulsória do migrante do território nacional, conjugada com o impedimento de reingresso por prazo determinado, sendo certo que a condenação com sentença transitada em julgado poderá ensejar a expulsão nos seguintes casos: crime de genocídio, crime contra a humanidade, crime de guerra ou crime de agressão, nos termos definidos pelo Estatuto de Roma do Tribunal Penal Internacional, de 1998; crime comum doloso passível de pena privativa de liberdade, consideradas a gravidade e as possibilidades de ressocialização em território nacional.

Por outro lado, são apresentados os casos que não são passíveis de expulsão, a saber: se implicar extradição inadmitida pela lei brasileira; e quando o expulsando tiver filho brasileiro que esteja sob sua guarda ou dependência econômica ou socioafetiva ou tiver pessoa brasileira sob sua tutela; tiver cônjuge ou companheiro residente no Brasil, sem qualquer discriminação, reconhecido judicial ou legalmente; tiver ingressado no Brasil até os doze anos de idade, residindo desde então no País; for pessoa com mais de setenta anos que resida no País há mais de dez anos, considerados a gravidade e o fundamento da expulsão; ou estiver vivendo no Brasil há mais de quatro anos anteriores ao cometimento do crime. ${ }^{20}$

\footnotetext{
19 Importante destacar o papel da Defensoria Pública da União em situações que versem a deportação: “Art. 51. Os procedimentos conducentes à deportação devem respeitar o contraditório e a ampla defesa e a garantia de recurso com efeito suspensivo. $\S 1$ ํㅡ A Defensoria Pública da União deverá ser notificada, preferencialmente por meio eletrônico, para prestação de assistência ao deportando em todos os procedimentos administrativos de deportação. § 2 ㅇ A ausência de manifestação da Defensoria Pública da União, desde que prévia e devidamente notificada, não impedirá a efetivação da medida de deportação." 20 Os artigos 58, 59 e 60 também apresentam aspectos importantes sobre a expulsão: Art. 58. No processo de expulsão serão garantidos o contraditório e a ampla defesa. $§ 1$ ํㅡ Defensoria Pública da
} 
Ao que parece, a nova $l \mathrm{e}^{21}$ brasileira, inspirada em princípios como o da não indiferença ${ }^{22}$, começa a atribuir o valor e importância para aqueles que, por motivos diversos, acabaram por deixar os seus países de origem.

\section{CONSIDERAÇÕES FINAIS: O QUE SE ESPERA A PARTIR DA NOVA LEI MIGRATÓRIA BRASILEIRA?}

A defesa de uma nova postura por parte dos Estados, diante das mais diversas e adversas situações que se manifestam no campo das relações internacionais, passou a ser uma necessidade premente e o princípio da não indiferença ${ }^{23}$ uma verdadeira bússola a orientar as práticas destes atores internacionais.

Há muitas situações que afetam as relações jurídicas que são produzidas na arena internacional, como por exemplo: crises econômicas; catástrofes ambientais; convulsão social; crime organizado; tráfico de drogas; rompimento com o Estado de Direito; fome, miséria e doenças; conflitos armados; e mais recentemente, embora não seja algo novo, as migrações, que ganhou destaque neste estudo.

O número de refugiados e migrantes ${ }^{24}$ económicos $^{25}$ tem aumentado significativamente, seja pela esperança de encontrar novas oportunidades e melhores condições, seja por razões de pobreza extrema, de catástrofes naturais, ou o pior de todos os motivos, da guerra. E, tanto os que fogem da miséria, como os que foram desalojados por fatores climáticos extremos, acidentes ambientais ou conflitos bélicos estão, na realidade, a tentar salvar o bem mais precioso: a vida.

União será notificada da instauração de processo de expulsão, se não houver defensor constituído. § 2을 Caberá pedido de reconsideração da decisão sobre a expulsão no prazo de 10 (dez) dias, a contar da notificação pessoal do expulsando. Art. 59. Será considerada regular a situação migratória do expulsando cujo processo esteja pendente de decisão, nas condições previstas no art. 55. Art. 60. A existência de processo de expulsão não impede a saída voluntária do expulsando do País.

${ }^{21}$ A lei 13445/2017 contempla vários outros aspectos, como por exemplo, o Capítulo VI versa sobre a opção de nacionalidade e da naturalização; o Capítulo VII trata do emigrante; o Capítulo VIII abarca as medidas de cooperação; o Capítulo IX versa sobre as infrações e das penalidades administrativas; além de outras matérias. Todavia, neste tópico do livro, priorizou-se apresentar as questões gerais sobre a nova lei e, posteriormente será apresentado estudo específico sobre a lei de migrações como um todo.

22 Vide a propósito a obra de GUERRA, Sidney. Direitos humanos: curso elementar. 5.ed. São Paulo: Saraiva, 2017.

${ }^{23}$ Idem.

${ }^{24}$ GIDDENS, Anthony. Sociologia. 4. ed. Porto Alegre: Artmed, 2005, p. 215 destaca que "em 1990, a população migrante do mundo foi de mais de 80 milhões de pessoas, 20 milhões das quais eram refugiadas. Esse número parece prestes a aumentar nos primeiros anos do século XXI, induzindo alguns estudiosos a rotularem essa época como a "era da migração"."

${ }^{25}$ GUERRA, Sidney; ACCIOLY, Elizabeth. O instituto jurídico do refúgio à luz do direito internacional e alguns desdobramentos na União Europeia. Revista Jurídica da UNICURITIBA, v. 2, n. 47, 2017. 
Muitos autores ${ }^{26}$ acentuam que o agravamento dos problemas que afligem a sociedade tem sido também produzidos pela globalização econômica, que gera prejuízos e despreza a condição humana, trazendo grandes sofrimentos para grande parcela da população mundial. Entre nós, Lindgren Alves acentua que a perda da substância dos direitos humanos na situação de globalização sem controle ${ }^{27}$ é especialmente visível no incremento gigantesco de fenômenos que antes se apresentavam menos ameaçadores ${ }^{28}$.

De fato, existem muitos problemas que afetam a humanidade e ensejam a tomada de providências a serem coordenadas no plano internacional, com repercussões no direito interno dos Estados nacionais. ${ }^{29}$ A necessidade de reverter o quadro negativo ${ }^{30}$, que afeta

${ }^{26}$ GIDDENS, Anthony. O mundo na era da globalização. Lisboa: Presença, 2000: "a globalização não está a evoluir de forma imparcial, e as suas consequências não são totalmente benignas. (...)a globalização tende a destruir as culturas locais, a aumentar as desigualdades do mundo e piorar a sorte dos empobrecidos."

${ }^{27}$ BARBOSA, Manuel Pinto, Globalização, desenvolvimento e equidade. Lisboa: Publicações Dom Quixote, 2001, p. 378, chama a atenção para a necessidade de se estabelecer mecanismos de controle sobre a globalização para que não se torne uma ideologia impositiva para os países e invoca o direito: "A globalização pode se transformar numa ideologia impositiva de interesses de países ou entidades. O mais forte antídoto contra esta ingerência de interesses particulares é constituído pelas instituições e pelo direito. Sem instituições, sem leis e sem governabilidade, a globalização pode tornar-se refém de grupos especiais de interesses".

${ }^{28}$ ALVES, José Augusto Lindgren. Os direitos humanos na pós-modernidade. São Paulo: Perspectiva, 2005, p. 211-212: “a) a imigração incessante e ascendente na Europa Ocidental e nos Estados Unidos, de pessoas procedentes de países pobres; b) o ressurgimento incontrolável do tráfico de pessoas e das formas contemporâneas de escravidão decorrente de dívidas; c) a rotinização da pornografia infantil e da pedofilia, associadas ao turismo sexual no terceiro mundo; d) o recrudescimento do racismo, envolvendo o reaparecimento de grupos nazifascistas e a consolidação de partidos ultranacionais; e) a explosão de conflitos fratricidas de micronacionalismos, como o da ex-Iugoslávia; f) o genocídio de coabitantes de uma mesma região, como ocorreu em Ruanda e ameaçou ocorrer em toda a área dos grandes lagos africanos; g) o crescimento exponencial do número de refugiados e pessoas deslocadas; h) a busca individual de proteção ou compensação contra as dificuldades vividas em seitas religiosas ou crendices sobrenaturais; i) a expansão do fundamentalismo religioso; j) o crescente recurso dos desesperados por ações violentas criminais ou suicidas; k) o aparecimento de uma nova rede de terrorismo com ações não reivindicadas e objetivos não explicitados pelos autores intelectuais."

${ }^{29}$ Pode ser apresentado como exemplo a situação atual que envolve o vizinho Estado venezuelano, cujo governo tem adotado severas práticas atentatórias aos direitos humanos, produzindo grande instabilidade política na região. Dentre os muitos efeitos das atrocidades praticadas na Venezuela de Nicolas Maduro, observa-se o grande fluxo migratório de venezuelanos para o Brasil que temem por suas vidas.

${ }^{30}$ Crise quintuplica número de imigrantes venezuelanos no Brasil. Desde 2014, mais de 12.000 pessoas cruzaram a fronteira para fugir da crise política, econômica e social no país de Maduro. 18 de abril de 2017. Disponível em http://veja.abril.com.br/mundo/crise-quintuplica-numero-imigrantes-venezuelanos-nobrasil/ Acesso em 16/05/2017: De acordo com relatório apresentado pela organização americana Human Rights Watch, divulgado nesta terça-feira, o número de venezuelanos que imigraram para o Brasil quintuplicou em 2016 comparado ao mesmo período de 2014. O documento atribui os dados à escassez de alimentos e medicamentos na Venezuela e pede que Caracas tome medidas de alívio para o colapso das instituições e serviços. Desde 2014, mais de 12.000 pessoas fugiram da crise política, econômica e social venezuelana em direção ao Brasil, principalmente no estado fronteiriço 
sistematicamente a pessoa humana no mundo global, faz com que ganhe eco e força, entre os mais diversos atores sociais, a observância da não indiferença." ${ }^{31}$

A não indiferença ${ }^{32}$ deve estar presente principalmente em momentos de desequilíbrio e grande convulsão social, como tem-se apresentado em vários países. No caso dos imigrantes, a situação que se apresenta no mundo atual é dramática e tem produzido uma crise sem precedentes em vários setores, onde por vezes, coloca-se em dúvida, a solidariedade, a compaixão, aspectos morais, o valor que deve ser atribuído ao direito, e o papel dos direitos humanos na sociedade hodierna.

Na Europa ${ }^{33}$, por exemplo, o número de refugiados que já se arriscaram pelo mar, apenas no ano de 2017, para aportar em solo europeu pelo caminho italiano, ultrapassou o número de 43 mil pessoas e isso tem gerado um grande desconforto por parcela significativa dos cidadãos europeus. ${ }^{34}$ Apesar de tudo isso, recentemente a grande preocupação que pairava

de Roraima. Apenas nos primeiros onze meses de 2016, 7.150 entraram no país. De acordo com o diretor das Américas da Human Rights Watch, José Miguel Vivanco, houve também um grande crescimento nos pedidos de asilo, de 54 em 2013, para 2.595 em 2016.

${ }^{31}$ Também nesta direção COMESAÑA, Antón Costas; CÉSPEDES, Gemma Cairó. Cooperación y desarrollo: hacya una agenda comprehensiva para el desarrollo. Madrid: Pirámides, 2003, p. 26: "Si pudiésemos conseguir actuar sobre una serie de factores para alcanzar un crecimiento con equidad, una buena gobernabilidad a nivel local, regional y mundial, reducir drásticamente la vulnerabilidad a la que están sometidas tantas personas por catástrofes y conflictos, incrementar la cantidad y la calidad de la ayuda oficial al desarrollo, y condonar la deuda externa para poder invertir en desarrollo humano, el panorama podría ser muy distinto. Esto no es una labor exclusiva de ONG, organismos de Naciones Unidas o gobiernos, sino de todos. Es necesario que todos tengamos una voluntad suficiente para ir mucho más allá de lo que a veces nos parece evidente, pero no siempre es suficiente."

32 Vide a propósito a obra de GUERRA, Sidney. Direito internacional ambiental. Rio de Janeiro: Freitas Bastos, 2006.

${ }^{33}$ Os dados foram divulgados pelo alto-comissário da ONU para Refugiados, Filippo Grandi, que alertou para as mortes e desaparecimentos, registrados desde o início do ano, de mais de 1,1 mil indivíduos durante a travessia. "A rota da região central do mar Mediterrâneo, entre o norte da África e a Itália, um dos caminhos mais usados pelos solicitantes de refúgio e pelos migrantes que vão para a Europa, se provou particularmente fatal. Disponível em https://nacoesunidas.org/tema/refugiados-migrantes/. Acesso em 17/05/2017.

${ }^{34}$ A Revista Isto é publica uma pesquisa realizada na Europa que apresenta dados estarrecedores sobre a visão que muitos europeus possuem sobre o fenômeno migratório, em especial em relação aos islâmicos. A matéria, em tom sensacionalista, apresenta o título "A Europa contra os imigrantes". Disponível em http://istoe.com.br/europa-contra-os-imigrantes/ Acesso em 17/05/2017: Em recente pesquisa elabora na União Europeia, onde se pergunta se deveriam ser adotadas medidas de contenção para que não ocorra a migração de maneira tão intensa e se a imigração de nações predominantemente islâmicas deveria ser barrada, verificou-se que mais da metade dos habitantes do Velho Continente concorda com o veto. Apesar de o sentimento contra refugiados ser mais intenso na Áustria, Bélgica, França, Hungria e Polônia, mesmo os lugares mais tolerantes apresentam índices extremamente altos de xenofobia. Entre os países consultados, a Espanha é o que tem a população mais aberta. Mesmo assim, $41 \%$ concordam que a entrada de imigrantes vindos de nações muçulmanas deveria acabar. Em nenhum local, mais de um terço discorda. Os achados também revelam como o anti-islamismo é especialmente intenso entre os mais velhos (60\%), os menos educados (59\%) e os que vivem no campo (58\%). No entanto, os números 
no velho continente, com a possível eleição presidencial de uma candidata da extrema direita (na França) e seus desdobramentos, foi superada. Novamente as milhares de pessoas que encontram-se na situação de não nacionais europeus ${ }^{35}$, mas que almejam um local seguro para passarem suas vidas, é de esperança.

Neste cenário obscuro, preocupante, tenso e indiferente que passa o mundo, com tantos conflitos e violações aos direitos humanos, o Estado brasileiro, que consagra a dignidade da pessoa humana como fundamento do Estado e princípio fundamental e ainda a prevalência dos direitos humanos, edita a nova lei de migração, em excelente hora, plenamente em consonância com o princípio da não indiferença, que se propõe a servir como axioma para a construção de uma sociedade que seja cada vez mais justa, inclusiva e protetiva dos direitos inerentes à pessoa humana.

Evidencia-se, pois, que o Brasil está no caminho certo ao conceber na ordem jurídica interna uma lei que consagra direitos e deveres para os não nacionais que encontram-se em território brasileiro, diferentemente do já revogado estatuto do estrangeiro, que limitava demasiadamente as atividades dos não nacionais.

A nova lei de migração chegou para contribuir, não apenas para com aqueles que encontram-se fora de seu país de origem, mas também para o Estado brasileiro, que além de possibilitar o ingresso e acesso incondicional para os imigrantes, tornando-os visíveis, proporcionará, por meio da participação dos mesmos, maior crescimento e inserção do país no cenário internacional, sendo possível afirmar que a lei 13445/2017 foi bastante benéfica para todo as pessoas que encontram-se na situação encampada pela lei, como também para o próprio Estado brasileiro.

ainda ficam perto da metade entre os mais novos, mais educados e que vivem nas cidades. "Na maioria dos estados onde a oposição é forte, a direita radical está entranhada como uma força política e busca mobilizar essa angústia contra o Islã nas urnas", afirma o relatório da pesquisa, realizada pelo instituto de relações internacionais Chatam House.

35 CASTELS, Stephen; MILLER, Mark apud GIDDENS, Anthony, op. cit., p. 216 identificaram quatro tendências que irão caracterizar os padrões de migração nos próximos anos: “a) aceleração - a migração através de fronteiras está ocorrendo em números maiores do que já ocorreu anteriormente; b) diversificação - atualmente, a maioria dos países recebe imigrantes de muitos tipos diferentes, ao contrário de antigamente, quando predominavam formas específicas de imigração, como a imigração de trabalho ou dos refugiados; c) globalização - a migração tornou-se mais global por natureza, envolvendo um número maior de países como emissores e receptores; d) feminização - um número crescente de migrantes é formado por mulheres, o que faz com que a migração contemporânea seja bem menos dominada pelo sexo masculino do que em épocas anteriores." 


\section{REFERÊNCIAS BIBLIOGRÁFICAS}

ALVES, José Augusto Lindgren. Os direitos humanos na pós-modernidade. São Paulo: Perspectiva, 2005.

ASANO, Camila Lissa; TIMO, Pétalla Brandão. A nova Lei de Migração no Brasil e os direitos humanos. Disponível em https://br.boell.org/pt-br/2017/04/17/nova-lei-de-migracao-no-brasile-os-direitos-humanos. Acesso em 03/05/2017.

BOBBIO, Norberto. A era dos direitos. Rio de Janeiro: Campus, 1992,

COMESAÑA, Antón Costas; CÉSPEDES, Gemma Cairó. Cooperación y desarrollo: hacya una agenda comprehensiva para el desarrollo. Madrid: Pirámides, 2003.

DAILLIER, Patrick; PELLET, Alain. Droit international public. 7. ed. Paris: LGDJ, 2002.

ENÉAS, Paulo. Ativismo digital contra a nova lei de migração. Disponível em http://criticanacional.com.br/2017/04/10/ativismo-digital-contra-nova-lei-de-imigracao/ Acesso em 16/05/2017.

GIDDENS, Anthony. O mundo na era da globalização. Lisboa: Presença, 2000.

Sociologia. 4. ed. Porto Alegre: Artmed, 2005.

GUERRA, Sidney. Direito internacional ambiental. Rio de Janeiro: Freitas Bastos, 2006.

Os direitos humanos na ordem jurídica internacional e reflexos para ordem constitucional brasileira. Rio de Janeiro: Lumen Juris, 2008.

Tratado de direito internacional. Rio de Janeiro: Freitas Bastos, 2008.

Curso de direito internacional público. 10 ed. São Paulo: Saraiva, 2016.

Direitos humanos: curso elementar. 5.ed. São Paulo: Saraiva, 2017.

GUERRA, Sidney; ACCIOLY, Elizabeth. O instituto jurídico do refúgio à luz do direito internacional e alguns desdobramentos na União Europeia. Revista Jurídica da UNICURITIBA, v. 2, n. 47, 2017.

Lei no 6.815, de 19 de agosto de 1980. Define a situação jurídica do estrangeiro no Brasil.

Lei no 13.445, de 24 de maio de 2017. Institui a lei de migração.

PIERRE, Renouvin; DUROSELLE, Jean Baptiste, Introducción a la historia de las relaciones internacionales. México, DF: Fondo de Cultura Económica, 2000.

Trabalho enviado em 30 de maio de 2017.

Aceito em 16 de outubro de 2017. 